ISSN 1870-4069

\title{
Ontology: Components and Evaluation, a Review
}

\author{
Cecilia Reyes-Peña, Mireya Tovar-Vidal \\ Benemérita Universidad Autónoma de Puebla, \\ Faculty of Computer Science, Puebla, Mexico \\ reyesp.cecilia@gmail.com, mtovar@cs.buap.mx
}

\begin{abstract}
The ontologies are a powerful tool for representing the knowledge from a particular domain so it is necessary to know its elements in order to guarantee the safety and satisfaction of the task for which was designed and created. This work presents a general review of the elements and evaluation of the ontology in order to offer practical definitions and some ontology application examples.
\end{abstract}

Keywords: Ontology, ontology's elements, ontology evaluation.

\section{Introduction}

All days the peoples generate a big information amount to share on the Internet, since a text message until the personal location. Sometimes there are problems when we want to consult, sort or transfer this information because the format is not the same in all sources. The ontology has the purpose of providing knowledge for data structuring by rules mainly on the web, from a particular domain.

We can define the ontology as a formal abstraction of what we wish to represent of a domain, using specific information such as objects, properties, and relationships [11] by a structure normally of hierarchical type; Tello [32] defines ontology as an explicit and formal specification about a shared conceptualization, that has a defined and legible vocabulary to express the main concepts and relationships about a specific domain [24]. The ontology also can be defined as a form of representation about a particular universe of discourse or some part [19], it has a well-defined structured from a set of most representational terms with human-readable text description and its construction methodology depend on clarifying what types of objects are researched in that domain [5].

In general, we can say that the ontology is a theory that specifies a relative vocabulary into a domain in order to help with the semantic interoperability among systems mainly in the web [18]. There are many kinds of ontologies according to their focus, application, creation, the specific domain, and generics [30].

In this work, the elements and evaluation techniques of an ontology are described in offering a general view about semantic knowledge representation and its evaluation from two approaches: validation and verification, and based on criteria. 
This work is structured as follows: in section 2, it describes the main elements which forming an ontology; section 3 contains evaluation techniques based on two approaches; section 4 contains the related works about the ontology application and finally, section 5 contains the conclusions and future work.

\section{Ontology's Elements}

The ontology can be seen as a 5-tuple where its components are: Concepts, relationships, functions, individuals or instances and axioms [32].

$$
\text { Ontology }=<C, R, F, I, A>\text {, }
$$

where:

- Concepts (classes): are the main formalized elements of the domain [32]. Since the logic, the concepts can be described using specific properties which must be satisfied by them [2].

- Relationships: are links between the concepts for representing the ontology structure (taxonomic or not taxonomic).

- Functions: are elements with the purpose of calculating information from the other elements.

- Instances (objects): are the representation about the main objects within domain according to ontology structure.

- Axioms: are the restrictions, rules, logic correspondences definitions [4] which must be accomplished in the relationship between the ontology elements. The axioms can be seen as the smallest unit of knowledge within an ontology [31].

Then, we can see an example of ontology about relevant information about the Master's degree in Computer Science (see Fig.1), where there are three taxonomies: Investigation Line, Person and Subject; a case of taxonomic relation is Student is-a Person [22] [26].

\section{Ontology Evaluation}

The ontology is a very important tool for the information representation that has become a standard for the knowledge representation [13], so it is necessary to evaluate its main aspects in order to guarantee that representation to be the most real according to the domain. The evaluation of an ontology can be seen from two approaches: verification and validation [1], or evaluation by criteria (see Fig.2).

\subsection{Verification}

The verification is used to determine if the ontology is correctly constructed or not by the satisfaction of the competency questions which was defined as part of the proposed task, i.e., if the built ontology is suitable for the real world. The verification has the next focus: 


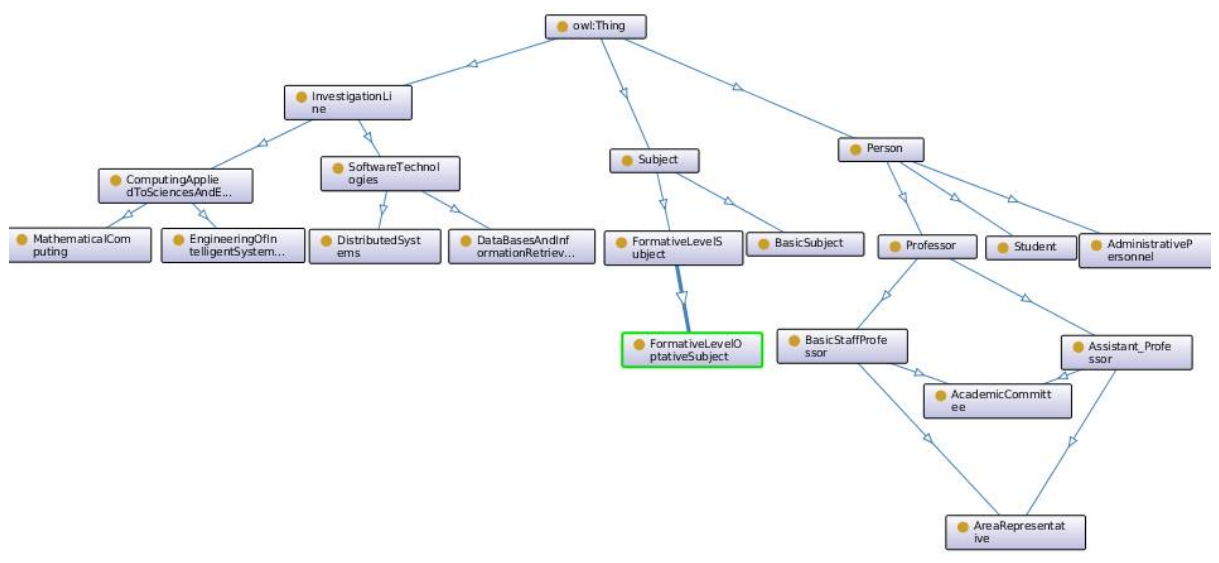

Fig. 1. Ontology Example: Master's degree in Computer Science.

- Lexical: the lexical verification is related to the vocabulary used for conceptualizing the domain and is regularly made with precision, recall and $F$-measure [31] [3]. This verification includes aspects related to the reusability $[15]$.

- Taxonomic: specifically, this verification is only focused on is-a and has-a relationships within the ontology.

- Semantic: is based on consistency by the semantic features of the ontology [37] considering the meaning and content of these features [15].

- Context: can be evaluated by other web ontologies or specific applications [28] which are in the same domain.

- Syntactic: this verification is about the coherence in the ontology definitions [28]. For a deep verification, it is necessary using some criteria [15].

- Structural, architectural and design: have the purpose to identify the absence of the main concepts of a domain in the structure, loops, concepts with the same definition but different name, among other errors. In this kind of verification does not exist metrics well defined because could be ambiguous [37] and normally the metrics are context-free [8].

\subsection{Validation}

The validation is about the ontology definitions which should most real possible model and represents a defined domain [24], i.e., indicates if the ontology definitions are a model of the real world [39]. The validation is made by the next techniques:

- Gold standard: In this validation, the ontology is compared with a gold ontology that was created by an expert, where both represent the same domain; it assumes the gold ontology is completed and corrected else the validation could have many errors [17] and is commonly used for ontology which was created by semi-automatic and automatic process [40]. 


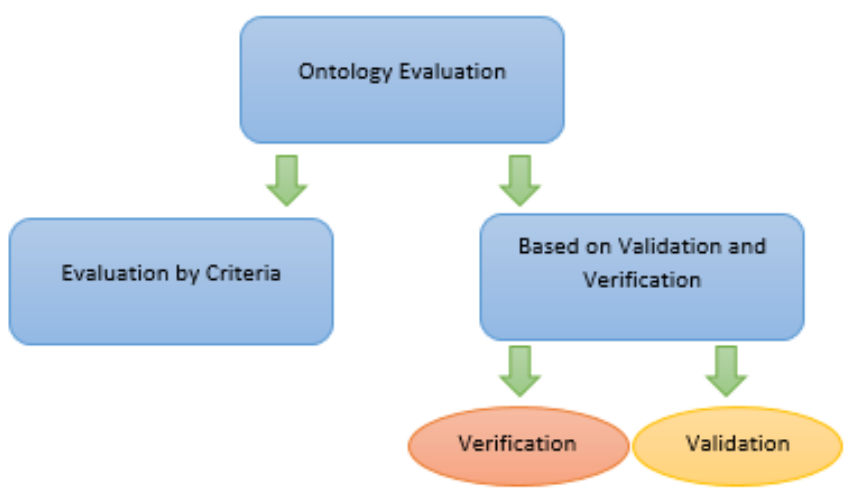

Fig. 2. Ontology Evaluation Approaches.

- Application based: the application based validation is a focus for determining if the results of the proposed ontology satisfy or not the task for which it was done [3].

- Data driven: for applying this validation is necessary to compare the information of the ontology with existing data about the same domain meanly using a corpus of text documents [3]. A very important aspect in this validation is determining if the ontology has enough elements for representing the domain [15].

- User based: basically, this validation is about the experience and perspective around the final user because it becomes suggestive and empiric; for minimizing the error it is advisable the user be an expert in the ontology domain [17].

\subsection{Evaluation by Criteria}

The evaluation by criteria is a focused technique in aspects or features which can be quantifiable [20] in order to ease the requirements analysis and some of them can be measured by ontology tool as reasoners [40]. In the Table 1 some criteria are described.

\subsection{Ontology Evaluation Related Works}

Wang et al. [38] developed an ontology using a geographic (spatial and temporal) knowledge of a gazetteer to associate natural hazards news reports by patterns; the main concepts are Happening for describing the processes that occur during 
Table 1. Criteria for the ontology evaluation.

\begin{tabular}{|c|c|}
\hline Criteria & Description \\
\hline Lawfulness & About the syntactical error frequency [3] \\
\hline Richness & $\begin{array}{l}\text { Quantifies the most important syntactic features } \\
\text { are used in the ontology }[3]\end{array}$ \\
\hline Adaptability & How the ontology responses in future uses [20] \\
\hline Clarity & $\begin{array}{l}\text { To communicate about the meaning of the terms } \\
\text { independently of the context [20] }\end{array}$ \\
\hline Closeness Index & $\begin{array}{l}\text { Measures the closeness or structural resemblance } \\
\text { among the concepts [14] }\end{array}$ \\
\hline Similarity Index & $\begin{array}{l}\text { About the proposition correctness into knowledge } \\
\text { structure [14] }\end{array}$ \\
\hline Accuracy & $\begin{array}{l}\text { Measures the representation of knowledge within } \\
\text { the ontology in relation to the real world [37] }\end{array}$ \\
\hline Coherence & $\begin{array}{l}\text { Measure if exist contradictions among the } \\
\text { elements of ontology according to logical } \\
\text { consistency }[37]\end{array}$ \\
\hline Computational Efficiency & $\begin{array}{l}\text { Measures the reasoner performance when } \\
\text { processing the ontology }[15]\end{array}$ \\
\hline Conciseness & $\begin{array}{l}\text { About the existence of irrelevant information } \\
\text { unnecessary and redundancies }[15]\end{array}$ \\
\hline Modularity & $\begin{array}{l}\text { Indicates if the ontology was created with an ap- } \\
\text { propriate methodology in order to define if exist } \\
\text { reusable components }[8]\end{array}$ \\
\hline Tangledness & $\begin{array}{l}\text { Measures the distribution of multiple concepts and } \\
\text { if exists intersections into the structure [40] }\end{array}$ \\
\hline Connectivity & $\begin{array}{l}\text { Indicates the most important concepts based on } \\
\text { the amount of relationships. [40] }\end{array}$ \\
\hline Consistency & $\begin{array}{l}\text { Indicates if exists a contradiction among the } \\
\text { definitions of the ontological elements }[10]\end{array}$ \\
\hline Completeness & $\begin{array}{l}\text { About if the content of the ontology is explicit on } \\
\text { can be inferred in order to consider it complete [10] }\end{array}$ \\
\hline Sensitiveness & $\begin{array}{l}\text { Measures how a small change in a definition } \\
\text { modifies other elements [10] }\end{array}$ \\
\hline Standard Coverage & $\begin{array}{l}\text { Identifies elements which are not defined in the } \\
\text { ontology [21] }\end{array}$ \\
\hline Coupling & $\begin{array}{l}\text { About the number of external concepts that are } \\
\text { referenced or imported [12] }\end{array}$ \\
\hline Coverage & $\begin{array}{l}\text { Indicates how well the ontology represents or } \\
\text { models the domain [12] }\end{array}$ \\
\hline
\end{tabular}


hazard events and object to indicate the involved entities, and the relationships are is-a and part-of type.

In the evaluation ontology area, Ying Shen el at. [29] propose an ontology evaluation approach based on entropy by three elements: data amount, data quality and finally, ontology structure and text visualization, for this, the ontology was seen as a graph where the entropy is measured between two elements and if the value is high it indicates that there is a high redundancy. Another work about evaluation was presented by Djuana [7], he evaluates a folksonomy-based ontology by gold-standard using some important references into state of the art in order to validate the coverage for wider the ontological elements.

There are algorithmic methods for semantic validation of UML (Unified Modeling Language) class diagrams using an ontology as a reference in the domain; the ontology determines if the elements and relationships into diagram are contradictory or not and if are into domain [27].

Barchini et al. [2] propose four dimensions for ontology evaluation since ontology quality approach: descriptive, structural, functional and operative; descriptive dimension refers how well the ontology gives information about its features, structural dimension about how the ontology specifies its elements and definitions, functional dimension about the ontology capacity for giving functions in order to satisfy specific requisites and operational structure determines the ontology capacity for integrating to other physical and logical agents. The ontology proposed by Tovar [33] is a tool for the search information about the social service in a higher level education institution was manually created and validated by the answers of some competency questions.

There is a methodology for ontology evaluation in restricted domains by lexico-syntactic patterns, grouping by formal concept analysis, similarity, latent semantic and dependence graphs using corpora as a reference providing a score based on accuracy measure [36]. Further, the latent semantic analysis is defined as a technique that assumes the words in a common context are semantically related [34].

There are ontology evaluate focus as ontology definitions, the software used for building, share and reusing elements and the documentation about its [9] and some of them are focused to evaluate only ontological elements as semantic relations [35].

\section{Ontology Applications Related Works}

The representation of the information as the main purpose of an ontology that is why we can many applications about the use of information extraction techniques belonging to NLP (Natural Language Processing) as a tool for ontology designing, creation and instancing. For example, to store the clinical histories of patients, didactic sequence design based on competencies used by an upper middle education professor approach and the creation of management of heterogeneous data system in a university. 
Kuna et al. [16] propose an ontology as an extension of an information retrieval system specifically in the query process, this work is designed for scientific document search in the computer sciences domain.

In the medical area, it has proposed to use an ontology for integrating information by heterogeneous way in order to create a repository using a similarity detection algorithm; for creating the mean ontology, it was necessary to mapping the known features to extend the domain [25]. Another application in the same area, it is the use of an ontology for enriching the diabetic patient education in a personalized way [23].

A case of use of an ontology is monitoring of a multi-agent system based on sensors; the ontology saves information about the system process and throws alerts when some sensor does not work on the different physical and logical components of the system [6].

\section{Conclusions and Future Work}

The ontology is an important standard for information representation, but also when is evaluated can infer knowledge in order to expand itself. We can say the ontology verification is made by measuring features and mathematical functions and the validation is guaranteed by knowledge previously given by an expert in the domain.

In the case of ontology evaluation by criteria, it can use the most appropriated criterion (or a set of them) according the kind of the ontology or its purpose. There is not an only strategy for ontology evaluation that guarantees the best performance, however the evaluation results will depend of a combining between the ontology purpose and the used strategy, in many cases.

Acknowledgement. This work is supported by the Sectoral Research Fund for Education with the CONACyT project CB-257357, and partially supported by the VIEP-BUAP.

\section{References}

1. Amith, M.F., He, Z., Bian, J., Lossio-Ventura, J.A., Tao, C.: Assessing the practice of biomedical ontology evaluation: Gaps and opportunities. Journal of biomedical informatics (2018)

2. Barchini, G.E., Álvarez, M.M.: Dimensiones e indicadores de la calidad de una ontología. Avances en Sistemas e Informática 7(1), 29-38 (2010)

3. Brank, J., Grobelnik, M., Mladenić, D.: A survey of ontology evaluation techniques (2005)

4. Chmielewski, M., Paciorkowska, M., Kiedrowicz, M.: A semantic similarity evaluation method and a tool utilised in security applications based on ontology structure and lexicon analysis. In: Mathematics and Computers in Sciences and in Industry (MCSI), 2017 Fourth International Conference on. pp. 224-233. IEEE (2017)

5. Couldry, N., Kallinikos, J.: Ontology (2018) 
6. Cruz, A.P.H., Ortega, C.A.P., Granados, L.A.P.: Diseño de una ontología para agentes que monitorean mediciones de sensores. REVISTA COLOMBIANA DE TECNOLOGIAS DE AVANZADA (RCTA) 2(26) (2017)

7. Djuana, E.: Gold-standard evaluation of a folksonomy-based ontology learning model. In: Journal of Physics: Conference Series. vol. 971, p. 012045. IOP Publishing (2018)

8. Gangemi, A., Catenacci, C., Ciaramita, M., Lehmann, J.: Modelling ontology evaluation and validation. In: European Semantic Web Conference. pp. 140-154. Springer (2006)

9. Gómez-Pérez, A.: Some ideas and examples to evaluate ontologies. In: Artificial Intelligence for Applications, 1995. Proceedings., 11th Conference on. pp. 299-305. IEEE (1995)

10. Gómez-Pérez, A.: Evaluation of ontologies. International Journal of intelligent systems 16(3), 391-409 (2001)

11. Hlomani, H.: Multidimensional Data-driven Ontology Evaluation. Ph.D. thesis (2014)

12. Hlomani, H., Stacey, D.: Approaches, methods, metrics, measures, and subjectivity in ontology evaluation: A survey. Semantic Web Journal 1(5), 1-11 (2014)

13. Huitzil, I., Straccia, U., Díaz-Rodríguez, N., Bobillo, F.: Datil: Learning fuzzy ontology datatypes. In: International Conference on Information Processing and Management of Uncertainty in Knowledge-Based Systems. pp. 100-112. Springer (2018)

14. Iqbal, R., Murad, M.A.A., Sliman, L., da Silva, C.P.: A mathematical evaluation for measuring correctness of domain ontologies using concept maps. Measurement 118, 73-82 (2018)

15. Jain, S., Meyer, V.: Evaluation and refinement of emergency situation ontology. Int J Inform Educ Technol 8(10), 713-719 (2018)

16. Kuna, H.D., Rey, M., Podkowa, L., Martini, E., Solonezen, L.: Expansión de consultas basada en ontologías para un sistema de recuperación de información. In: XVI Workshop de Investigadores en Ciencias de la Computación (2014)

17. Lourdusamy, R., John, A.: A review on metrics for ontology evaluation. In: 2018 2nd International Conference on Inventive Systems and Control (ICISC). IEEE (2018)

18. Luna, J.A.G., Bonilla, M.L., Torres, I.D.: Metodologías y métodos para la construcción de ontologías. Scientia et technica 2(50), 133-140 (2012)

19. Martinez-Gil, J., Alba, E., Aldana-Montes, J.F.: Optimizing ontology alignments by using genetic algorithms. In: Proceedings of the workshop on nature based reasoning for the semantic Web. Karlsruhe, Germany (2008)

20. McDaniel, M., Storey, V.C., Sugumaran, V.: Assessing the quality of domain ontologies: Metrics and an automated ranking system. Data \& Knowledge Engineering 115, 32-47 (2018)

21. Olifer, D.: Evaluation metrics for ontology-based security standards mapping. In: Electrical, Electronic and Information Sciences (eStream), 2015 Open Conference of. pp. 1-4. IEEE (2015)

22. Peña, C.R., Vidal, M.T., González, C.S.V.: Creation of a consulting tool and implementation of an ontology for a master's degree program in computer sciences. Revista Colombiana de Computación 19(1), 29-38 (2018)

23. Quinn, S., Bond, R., Nugent, C.: A two-staged approach to developing and evaluating an ontology for delivering personalized education to diabetic patients. Informatics for Health and Social Care 43(3), 264-279 (2018) 
24. Ramos, E., Núñez, H., Casañas, R.: Esquema para evaluar ontologías únicas para un dominio de conocimiento. Enlace 6(1), 57-71 (2009)

25. Ren, S., Lu, X., Wang, T.: Application of ontology in medical heterogeneous data integration. In: Big Data Analysis (ICBDA), 2018 IEEE 3rd International Conference on. pp. 150-155. IEEE (2018)

26. Reyes, C., Tovar, M., Vázquez, S.: Ontology for the description of a masters degree program in computer sciences. In: Proceedings of the XVIII International Conference on Human Computer Interaction, Interacción 2017, Cancun, Mexico, September 25-27, 2017. pp. 12:1-12:4 (2017), http://doi.acm.org/10.1145/3123818.3123836

27. Sadowska, M., Huzar, Z.: Semantic validation of uml class diagrams with the use of domain ontologies expressed in owl 2. In: Software Engineering: Challenges and Solutions, pp. 47-59. Springer (2017)

28. Sekandar, K.: A quality measure for automatic ontology evaluation and improvement. Master's thesis (2018)

29. Shen, Y., Chen, D., Yang, M., Li, Y., Du, N., Lei, K.: Ontology evaluation with path-based text-aware entropy computation. In: The 41st International ACM SIGIR Conference on Research \& Development in Information Retrieval. pp. 881-884. ACM (2018)

30. Smith, B.: Ontology and information systems, forthcoming in stanford encyclopedia of philosophy. Recuperado de http://ontology. buffalo. edu/ontology (PIC). pdf. Fecha de consulta 20 (2003)

31. Ta, C.D., Thi, T.P.: Automatic evaluation of the computing domain ontology. In: International Conference on Future Data and Security Engineering. pp. 285-295. Springer (2015)

32. Tello, A.L.: Ontologías en la web semántica. España: Universidad De Extremadura (2001)

33. Tovar, M., Flores, J.C., Reyes-Ortiz, J.A.: An ontology for representing information over social service in an educational institution. In: DATA. pp. 391-399 (2017)

34. Tovar, M., Pinto, D., Montes, A., González, G.: An approach based in lsa for evaluation of ontological relations on domain corpora. In: Mexican Conference on Pattern Recognition. pp. 225-233. Springer (2017)

35. Tovar, M., Pinto, D., Montes, A., González, G., Vilarino, D.: Identification of ontological relations in domain corpus using formal concept analysis. Engineering Letters 23(2) (2015)

36. Tovar Vidal, M., Pinto Avendaño, D.E., Montes Rendón, A., González Serna, J.G.: A metric for the evaluation of restricted domain ontologies. Computación y Sistemas 22(1) (2018)

37. Vrandečić, D.: Ontology evaluation. In: Handbook on ontologies, pp. 293-313. Springer (2009)

38. Wang, W., Stewart, K.: Spatiotemporal and semantic information extraction from web news reports about natural hazards. Computers, environment and urban systems 50, 30-40 (2015)

39. YILMAZ, T.K., Durak, U., OĞUZTÜZÜN, H., ÇAĞGILTAY, K.: Usability evaluation of a web-based ontology browser: the case of tsont. Turkish Journal of Electrical Engineering \& Computer Sciences 26(2), 1115-1128 (2018)

40. Yu, J., Thom, J.A., Tam, A.: Ontology evaluation using wikipedia categories for browsing. In: Proceedings of the sixteenth ACM conference on Conference on information and knowledge management. pp. 223-232. ACM (2007) 